\title{
História e Musicologia: duas apropriações do passado
}

\author{
History and Musicology: two appropriation of the past
}

\author{
Denise Scandarolli \\ denisescandarolli@gmail.com \\ Bolsista Pós-Doutorado (Fapesp) \\ Universidade Estadual de Campinas \\ Rua Oshita Sigrist Pongelupe, 1113, torre 5, ap 2. \\ 13140750 - Paulínia - São Paulo \\ Brasil
}

\section{Resumo}

Este texto aborda as trajetórias da história e da musicologia enquanto disciplinas acadêmicas. Busca compreender seus diálogos e distanciamentos estabelecidos no processo de construção do conhecimento histórico e evidenciados pelas problemáticas trazidas por um objeto de estudo específico, a música. Dessa maneira, este trabalho visa apresentar de forma abrangente, questionamentos referentes às relações estabelecidas entre a musicologia e a história, considerando que ambas buscam o estudo do passado, no processo que as levou ao lugar de áreas de conhecimento específicos, com o intuito de proporcionar novos espaços de discussão e reflexões sobre a abertura de maior diálogo entre as duas disciplinas.

\section{Palavras-chave}

História; História das ideias; História da historiografia.

\section{Abstract}

This text approaches the paths of the history and the musicology, as academic disciplines. It's also aims to understand their dialogues and detachment established in the historical knowledge construction process and highlighting by the problematic brought by a specific object of study, the music. Thus, this work aims to present a comprehensive manner, questions concerning the relations between musicology and history considering that both seek the study of the past, in the process that led them to the place of specific areas of knowledge, in order to provide new spaces for discussion and reflections about opening more dialogue between the two disciplines.

\section{Keywords}

History; History of ideas; History of historiography. 
Durante o processo de estruturação da História e da Musicologia como conhecimento específico, ou seja, disciplinas com diretrizes aceitas por determinado grupo acadêmico, houve distanciamentos e diálogos estabelecidos entre estas duas áreas, que apesar de terem se firmado de forma singular no decorrer do século XX, são bastante próximas por tratarem, ambas, da ação do homem no tempo, ou mais especificamente, manter relações estabelecidas pela percepção dos tempos presente, passado e futuro em suas análises. As discussões que aproximam história e musicologia são amplas e muito recentemente começaram a ser debatidas, por isso, este texto tem como objetivo apresentar, de forma abrangente, alguns pontos referentes a esta temática, com o intuito de promover maiores reflexões e abrir cada vez mais espaço ao diálogo entre estas duas áreas de estudo.

Desde o final da década de 1980, mais precisamente a partir dos eventos ocorridos em 1989, em especial a queda do muro de Berlim, as ciências humanas viram-se envoltas em uma crise epistemológica, cujo questionamento de suas premissas e métodos abalou profundamente a credulidade nas obras anteriores (HARTOG 2013, p. 165). No caso da História, o impacto da desesperança com o futuro, as mudanças sociais, interpretados por François Hartog como a quebra do regime de historicidade moderno, futurista, e a passagem para um regime de historicidade presentista, fez com que os paradigmas da disciplina fossem questionados, ao limite de alguns autores decretarem este período como o fim da história (FUKUYAMA 1999; DOSSE 2003).

226 Da mesma forma que a história, a musicologia começou a questionar suas certezas epistemológicas e, sobretudo, a rigidez com a qual suas fronteiras foram mantidas dentro do universo acadêmico, pouco abertas ao diálogo interdisciplinar. Na França, alguns trabalhos como os de Philippe Bachman, Philippe Vendrix e Myriam Chimènes, todos publicados durante a década de 1990, buscam trazer à tona discussões envolvendo as pesquisas e produções acadêmicas em musicologia, principalmente referentes à musicologia histórica. Estes autores apontam a necessidade de se estabelecer um diálogo entre a história e a musicologia, já que, como afirma Myriam Chimènes, tanto musicólogos quanto historiadores ignoraram-se reciprocamente durante décadas.

A percepção por parte de alguns pesquisadores europeus deste isolamento epistemológico, no qual se encontrava a musicologia histórica, levou a Sociedade Francesa de Musicologia a organizar Jornadas de Estudos, buscando debater a disciplina, seus métodos, objetivos e seu futuro. No decorrer do ano de 1996, dois destes encontros foram realizados, contando com a participação de historiadores, musicólogos e historiadores da arte. No Brasil, neste mesmo período, alguns pesquisadores também iniciaram reflexões bastante frutíferas sobre os procedimentos epistemológicos adotados pela musicologia e sobre os paradigmas abordados pela disciplina, sobretudo por sua vertente histórica, além de lançarem tentativas de aproximar os estudos musicais e os estudos históricos (BARROS 2015; BARROS 2013a; BARROS 2013b; BLANCO 2004; ASSIS 2009; BLOMBERG 2011; SANT'ANNA 2016). 
A musicologia histórica foi classificada por Myriam Chimènes em meados da década de 1990, como sendo "terra de ninguém", cujo desbravamento está em curso e cuja conquista necessita de colaborações interdisciplinares. Para esta musicóloga francesa, o distanciamento mantido pelos historiadores em relação à música pode ser entendido como certa timidez face a um objeto de acessibilidade e de legibilidade diferente. Por outro lado, ela argumenta que os musicólogos também se mantiveram alheios aos questionamentos levantados pela história, no decorrer de todo o século XX. É justamente este estranhamento mútuo o que este trabalho pretende discutir.

Antes da institucionalização da história e da musicologia, processo que separou as áreas de atuação e objetos destinados a cada uma, os estudos do passado foram tomados por diferentes formas de representação. No que diz respeito aos estudos da história da música, Vendrix afirma que dois critérios foram necessários para o surgimento de uma demanda histórica acerca do domínio das produções artísticas. O primeiro critério é o formal: a história da música teria começado com o reconhecimento do princípio de aplicação de um método que permitisse fornecer às manifestações de criação musical relações de referência no tempo e no espaço. Estas relações passaram a existir depois que alguns autores tomaram consciência, nos idos do século XV e XVI, da importância da criação artística no decorrer da história, a qual repousaria sobre fundamentos de um verdadeiro "espírito histórico". O segundo critério se sustenta sobre a oposição entre o discurso normativo e o discurso histórico (VENDRIX 2004, p. 71).

A obra de Gioseffo Zarlino, Istitutioni harmoniche, de 1558, sistematiza esta oposição, propondo dividir todos os estudos teóricos da música em duas partes: a história e o método. O método consistiria no estudo dos corpos sonoros, os quais Joseph Sauveur viria a chamar de acústica, no início do século XVIII. Quanto à história, se referiria ao estudo dos corpos sonoros por meio de manifestações escritas e de interpretação das obras por compositores de diferentes épocas, ou seja, o estudo de fontes históricas por meio dos princípios da análise textual definida pelos humanistas (VENDRIX 1993, p. 153).

Este sistema hermenêutico também estava presente nos estudos históricos de maneira geral. O período em que a obra de Gioseffo Zarlino foi escrita marca mudanças na importância do futuro para a escrita da história. Na renascença, período de desenvolvimento tecnológico, das navegações, das Reformas religiosas e da chegada dos europeus ao "Novo Mundo", surge uma nova experiência de temporalidade, a qual compreende novas categorias de história, como a história Humana e a história Natural separadas da história religiosa, cujo horizonte de expectativa, em vez do fim do mundo previsto pela concepção de história anterior, inaugura como futuro um tempo diferente e novo (KOSELLECK 2006, p. 25). A partir de então, o período anterior passa a ser visto como superado, inferior ao presente, o mesmo que elege um passado ideal como representativo do porvir, a antiguidade clássica, relegando a Idade Média à Idade das Trevas. Os conceitos - antiguidade, Idade Média e Idade Moderna - já se encontravam disponíveis desde o Humanismo, assim o tempo do renascimento era superior 
ao período anterior por ter sido compreendido como fruto do reencontro com o passado clássico (KOSELLECK 2014, p. 257).

Da mesma forma, no que diz respeito aos domínios da música, só o novo mereceu a atenção neste período. As composições do passado não eram vistas como artefato com qualidade inerente que fosse necessário ser preservado. A noção de repertório é estranha às práticas dos séculos XV e XVI, salvo raras exceções. Por outro lado, algumas obras como o Dictionnaire de la musique (1703), de Sébastien de Brossard, o Musicalisches Lexikon (1732), de Johann Gottfried Walther e o Esemplare a sia saggio fondamentale pratico di contrappunto (17741775), de Giambattista Martini, tem como objetivo a curiosidade e a coleção, transformando a história da música em um agrupamento de experiências, a exemplo de algumas outras obras como a de autoria de Jacques BonnetBourdelot (Histoire de la musique et de ses effets 1715), de Battista Martini (Storia della musica, 1757-1781), de Charles Burney (A general history of music 1776-1789) e de Jean-Benjamin de Laborde (Essai sur la musique ancienne et moderne 1781).

Esse papel do colecionador de fatos e curiosidades, o antiquário, aquele que reúne, compara e classifica, monumentalizando o passado, também estava presente na escrita da história. Mas, a vertente considerada oficial da história, escrita por aqueles que eram conhecidos como historiadores eruditos, consistia em narrativas dos feitos heróicos dos reis e nobres, as quais tiveram papel importante na estruturação representativa do Estado moderno. A crítica 228 a esta forma de narrativa histórica foi feita de maneira mais sistemática pelos filosofo iluministas do século XVIII. Os questionamentos sobre o tempo e sobre o sentido da história trazidos pelos filósofos setecentistas eram concebidos a partir da noção de progresso e, assim como a noção de verdade, é cara a estes pensadores, em especial aos franceses, como Pierre Bayle, J. J. Rousseau, Voltaire e Condorcet, independentemente de sua percepção pessimista ou não do passado posto em relação ao futuro. Neste sentido que Koselleck afirma ter sido com o advento da filosofia da história que uma incipiente modernidade se desligou de seu passado, inaugurando, por meio de um futuro inédito, também o período que se convencionou a chamar de modernidade. Esse progresso, define Koselleck, se desenvolve na medida em que o Estado e seus prognósticos não eram capazes de satisfazer as exigências soteriológicas (KOSELLECK 2006, p. 28).

Reflexões sobre a música estavam presentes nos trabalhos dos filósofos do século XVIII, em obras como as de J. J. Rousseau - Projet concernant de nouveaux signes pour la musique; Dissertation sur la musique moderne; Lettre sur la musique française, entre outros. O conceito de progresso presente em outras áreas de estudo permeia também os estudos da música, a exemplo da explicação progressista dos sistemas composicionais, aparecendo de maneira bastante contundente como base da elaboração de uma ideia de progressão e melhora dos elementos musicais no decorrer do tempo. Sendo assim, a evolução musical torna-se progressiva e representativa da evolução do pensamento humano. 
Contudo, a visão progressista da análise musical sofre modificações, por volta da virada do século, aparecendo nos estudos das artes outro argumento de que certas obras poderiam reivindicar um valor artístico permanente, como defende François-Joseph Fétis (1784-1871) em La musique mise à la portée de tout le monde: exposé succinct de tout ce qui est nécessaire pour juger de cet art, e pour en parler sans l'avoir étudié, publicado em Paris, em 1830. Dessa forma, subverte-se a ideia de progresso na ideia de transformação, pois a concepção progressista anularia por si só a lógica de qualidade inerente de uma obra anterior se comparada às produções contemporâneas.

A reivindicação de um valor histórico permanente para a obra de arte apoia-se, no século XIX, em uma definição mais abrangente: a ideia de clássico, definido como obras universais aquelas que constituem um bem comum à humanidade e também um patrimônio nacional. Mas, a escolha de quais obras poderiam ser consideradas como tal dependia de todo um julgamento de valor repousado na exclusão.

As concepções de história, de passado e tempo sofreram modificações desde meados do século XVIII, deixando de significar as múltiplas narrativas das experiências passadas (Historie), se seguirmos as definições de Koselleck, para referir-se à construção narrativa destas experiências (Geschichte). Pelo menos simbolicamente, como argumenta Hartog, o ano de 1789 pode datar uma mudança na percepção do tempo, um novo regime de historicidade, no qual a categoria do futuro se faz preponderante. Neste novo regime de historicidade o tempo passa a ser percebido como aceleração, o exemplar deu lugar ao único. $\mathrm{O}$ acontecimento converteu-se àquilo que não se repete. O presente rompe definitivamente com o passado (HARTOG 2013, p. 167).

Em meio a esta concepção temporal os estudos sobre o passado institucionalizaram-se, buscando estruturar uma linguagem científica aos moldes das ciências da natureza. Na história, este processo constituiu a percepção de um tempo histórico linear, em base cumulativa e irreversível, correspondendo especificamente a uma história política. Para os historiadores deste período o passado está morto, sendo possível acessá-lo somente por meio das pesquisas de fontes confiáveis, como os documentos oficiais. A institucionalização da escrita da história também direcionou as temáticas pesquisadas, as quais tiveram como foco a história da nação, dando forma às narrativas nacionais e crítica à concepção filosófica da história.

Este contexto é a base da afirmação de Vendrix sobre a história da música, de que a crítica histórica do século XIX é relativista e descritiva: ela se opõe à tradição clássica, absolutista e prescritiva que julgava toda obra em relação às normas atemporais. É justamente esta nova crítica aos estudos da música que funda, segundo o autor, a filologia e a história da música. Estas duas disciplinas compartilhavam a ideia de que o compositor e sua obra deveriam ser compreendidos em meio a sua situação histórica, ou seja, a percepção da temporalidade e não mais a análise das obras de forma atemporal. Entretanto, o discurso sobre a música passou a privilegiar biografias, cuja atenção era concentrada sobre a trajetória de vida de alguns poucos compositores, 
escolhidos como ícones de determinado período, ou a realização de catálogos, como dicionários biográficos históricos, a exemplo das obras de Choron et Fayolle, Dictionnaire historique des musiciens (1810-1811), Ernst Gerber, Nouveau lexique historique et biographique des compositeurs (1812) e de Fétis, Dictionnaire des musiciens (1824) e Dictionnaire biographique universel (18331844). Semelhante à história, a musicologia neste período também concebe como prática de apropriação do passado a produção cronológica do tempo, que dispõe os fatos eleitos, à priori, como principais representantes do período narrado, forjando uma coerência ao encadeá-los como mais importantes na sua reconstrução, em ordem crescente no tempo histórico, do passado ao agora.

A fundamentação metodológica também é um ponto em comum no processo de estruturação das duas disciplinas, com a valorização de práticas empíricas, os quais vislumbravam métodos de seleção, leituras e análises das fontes. Alguns autores destacaram-se na pesquisa da história, principalmente durante a segunda metade do século XIX. Na Alemanha, pode-se dizer que duas escolas históricas se sobressaíram: a Escola Rankeana e a Escola histórica Prussiana, sendo assim, o pensamento histórico germânico passa por pesquisadores como Leopold von Ranke, Heinrich von Sybel, Barthold Georg Niebuhr, Johann Gustav Droysen, Georg Gottfried Gervinus, entre outros (BENTIVOGLIO 2011; SCHOLTZ 2011). Na França, outros historiadores, entre eles G. Monod, Langlois e Seignobos, buscavam seguir métodos empíricos para a escrita da história, enfatizando a objetividade dos estudos do passado e a verificação da certeza do fato por meio 2.30 de documentos "inquestionáveis", aqueles produzidos pelos órgãos oficiais. Conhecidos como metódicos, eles fundaram a chamada Revista Histórica, em 1876, como contraposição aos trabalhos pautados na narrativa romântica, da qual um dos principais representantes foi Jules Michelet (LE GOFF 2013; DOSSE 2003; BOURDÉ 1983).

De certa forma, a criação de revistas específicas de estudo, como a Historische Zeitschrift (1859), a Revue Historique (1876), assim como os Annales d'histoire économique et sociale (1929), New Left Review (1960) e a Revista Quaderni Storici (1966), foi definindo as fronteiras entre as disciplinas institucionalizadas no decorrer do século XIX e início do XX. Seguindo o mesmo movimento que outras áreas de conhecimento, vários periódicos especializados em musicologia foram criados. Na França foi fundada a Revue d'histoire et de critique musicales (1901), na Alemanha a Die Musik (1901) e a Mitteilungen der International en Gesellschaft für Muzikwissenschaft (1929). A criação destas revistas foi possível graças à abertura de espaços de discussão, dentro das universidades, sobre temas relacionados à história e aos conhecimentos musicais. A partir de 1850, um certo número de cadeiras de musicologia foi criado, apoiadas pelos Estados europeus para promover a pesquisa científica nas artes musicais em geral e a de história da música em particular. A temática envolvendo os processos de nacionalização das sociedades europeias, nas últimas décadas do século XIX, apresentou-se como uma obrigação para os musicólogos, a de participar ativamente da elaboração e da difusão da memória coletiva, forjando uma 
identidade nacional (VENDRIX 2004, p. 78). Papel que vinha sendo exercido também pela história desde a primeira metade do século XIX.

De certa forma, logo que a história da música se instituiu como disciplina de ensino superior, artística e universitária, ela se distanciou da crítica e da análise musical, criando uma separação que começará a ser questionada pela teoria da musicologia somente a partir da segunda metade de década de 1940.

Desde sua estruturação enquanto disciplina, a história da música centrou suas narrativas na perspectiva de exposição cronológica dos fatos, elencando apenas os compositores e composições considerados clássicos, em um sistema de exclusão, que silenciava as obras musicais que não pertenciam ao cânone dos principais autores europeus, os quais exemplificavam o desenvolvimento civilizatório daquelas sociedades. Sendo assim, a história da música foi resumida a alguns poucos compositores, músicos e interpretes já consagrados, representantes da genialidade artística do passado, endossando dessa forma, o próprio conceito de gênio forjado no século XIX. ${ }^{1}$ Além disso, como aponta Vendrix, a musicologia pautou sua vontade de autonomia rejeitando, como intromissão intolerável, todas as interrogações e as críticas vindas das outras ciências.

Dessa forma, a narrativa que sustentou os escritos históricos e musicológicos até a primeira metade do século $X X$, fundava-se na concepção de um passado estático, alcançado apenas por meio de fontes objetivas, as quais funcionavam como ponte entre o presente e o passado. Por outro lado, a competência de leitura das fontes, consideradas capazes de fundamentar a escrita do passado elaborada pela história da música, também foi responsável pelo afastamento entre a musicologia histórica e a história. Para os pesquisadores da história da música, as obras musicais consistem em importantes documentos que legitimam e ressaltam a importância dos autores canônicos. Nestas abordagens, a progressão da técnica musical acompanha o progresso da sociedade na qual determinado compositor estava inserido. Apesar de se aproximarem na concepção narrativa e na forma de apropriação do passado, a história da música e a história mantiveram seus domínios demarcados, sobretudo, pela característica singular das fontes musicais, as quais demandavam ferramentas específicas para a sua compreensão, sendo necessário determinado grau de domínio de teoria musical ou composição musical para conseguir compreender uma partitura.

Depois da Primeira Grande Guerra e da recessão econômica do final da década de 1920, as certezas cunhadas em um passado glorioso, o qual levaria a um futuro de sucesso, foram postas em xeque. A objetividade do conhecimento do passado foi problematizada pelas ciências humanas com base nas incertezas do presente. A sociologia e a economia ganharam espaço, questionando a legitimação do discurso histórico do passado. A ideia de que "a história apenas dá sentido ao que não tem mais sentido" (HARTOG 2009, p. 171), como cita Hartog, inundou os espíritos de alguns historiadores. Determinados questionamentos, como o do evolucionismo e da ideia de progresso, deslocaram a reflexão da 
história para outros terrenos, exteriores ao seu próprio território. Este período é marcado pelas novas ciências sociais, como a linguística, a psicanálise, a antropologia, por ciências que tinham como objeto o estudo da sociedade (DOSSE 1992).

Frente aos apontamentos trazidos pela sociologia, sobretudo a sociologia de Durkhein, na França, alguns historiadores distantes do tradicional centro de estudos históricos da Sorbonne, fundaram em Strasburgo a revista Annales d'Histoire Économique et Sociale. Estes historiadores defendiam novos paradigmas, questionando alguns pontos fundamentais presentes na escrita da história dos historicistas e dos metódicos, como a ideia de objetividade do conhecimento histórico e dos documentos do passado, da construção narrativa do passado baseado na colocação dos eventos de forma cronológica, assim como a ideia de que a única história possível era a história política (BLOCH 2001; FEBVRE [s/d]; DOSSE 1992; DOSSE 2004).

Para a historiografia francesa, o Annales, que tinha como principais representantes em sua primeira fase Marc Bloch e Lucien Febvre, trouxe importantes avanços nos estudos do passado, pois questionava o passado estático defendendo uma história interpretativa, comparativa, global, concebida como uma história-problema e como uma história em construção (BLOCH 2001). O pressuposto é o de que a história se constitui nos quadros das grandes referências do conhecimento possível de um período singular, uma vontade teórica de sintetizar a dinâmica das rupturas e a inércia das permanências, na 2.32 perspectiva de um grande movimento da história da civilização. Uma história que incorpora os elementos de concepções divergentes, considerando os interesses científicos de cada área de conhecimento, vistas como ciências auxiliares, mas que sempre se reporta a uma realidade de abrangência superior, a civilização como experiência humana geral (FEBVRE; BERR 1932).

Dessa forma, reforçam a natureza epistemológica de uma "história problema", na qual o passado é uma elaboração problematizada e construída pelo historiador, a partir de questões postas pelo seu próprio presente, tendo a "verdade histórica" assumido um novo sentido, transformando-se na discussão sobre os processos de produção do conhecimento histórico, assim como considerando as partes que o constituem, seu sujeito, objeto e fontes.

Os documentos, que antes eram vistos como reflexo da realidade, passaram a ser analisados como produto de um grupo social inserido em determinado tempo e espaço. Sendo assim, eles não representam a verdade explicita, mas os interesses e ideologias de quem os produziram. Outro ponto de destaque e crítica à escrita da história anterior refere-se à narrativa linear do tempo histórico. Como, para o Annales a escrita da história só é possível por meio de questionamentos feitos ao passado, a linearidade passa a ser vista como uma apropriação artificial do tempo, uma compilação artificial dos eventos, os quais não representam a totalidade da história, mas sim a escolha subjetiva do autor da narrativa.

Não só os historiadores franceses estavam questionando a objetividade do processo de produção do conhecimento histórico. Outras vertentes de estudos 
históricos também relativizaram os paradigmas historiográficos anteriores. Um exemplo é a Nova História americana, que teve em Carl Becker um importante representante. Becker sustentava a ideia de que os fatos do passado precisavam da experiência do presente para ter significado, abrindo a discussão para a percepção de um relativismo histórico marcado pela percepção de que o historiador está inserido em seu próprio tempo e este contexto marca seus escritos sobre história (BECKER 1931, p. 221-36). Esta corrente historiográfica relativizava o viés empirista dos historiadores marcados pela busca da objetividade científica, adotando conceitos advindos das ciências sociais.

Mas, "a crise do espírito", como apontam as reflexões de Paul Valéry (1957), publicadas em 1919, não atingiu o ofício do historiador da música com o mesmo impacto que atingiu a história. A "História problema", cujo foco era o questionamento do passado por questões do presente e a consciência da subjetividade das fontes, assim como dos autores, não encontrou espaço nos escritos da história da música, a qual permaneceu fiel à narrativa linear, cronológica e objetiva da história estática, que tinha como seus representantes aqueles já consagrados por sua genialidade. O cânone de gênios era mantido como premissa. A história da música, como passado imutável, continuava a ser estruturada com base na divisão temporal apresentada pela historiografia oitocentista e por periodizações originadas nas artes, como período clássico, neoclássico, renascimento, barroco, romântico, etc., períodos vistos como sucessivos e progressivos. Além disso, não foi pensado nenhum tipo de crítica historiográfica, já que o passado é apreendido e não analisado, as narrativas tendiam a ser apenas reproduzidas, transformando-se em verdades e legitimação da superioridade artística de alguns artistas e suas obras.

A percepção das diversas temporalidades, assim como das alteridades culturais também não foram consideradas nos estudos da história da música da primeira metade do século $X X$, os quais ficaram alheios ao conceito de anacronismo e à preocupação com análises e julgamentos não condizentes com o período estudado. Sendo assim, obras como A history of Western Music, de Donald J. Grout e Claude V. Palisca, ou History of music, de Roy Bennett, ou ainda Tout l'Opéra, de Gustave Kobbé, caracterizam-se como trabalhos extensos, panorâmicos, factuais e cronológicos, marcados por juízos de valores e que buscam o esgotamento da temática, supondo apresentar o domínio de toda a amplitude da História da Música.

Foi apenas nos anos de 1970 que houve uma tentativa real de crítica epistemológica da musicologia histórica, discutida em especial na obra do musicólogo alemão Carl Dahlhaus (1928-1989). De forma geral, os questionamentos internos à musicologia opunham a teoria musical e a história da música, sendo a última acusada de delimitar seu objeto de estudo a um processo histórico que não reconhecia e nem tinha o domínio das especificidades da música em si. Em oposição a esta ideia, Dahlhaus buscou promover uma forma de historiografia que fosse o contraponto e o complemento lógico da história social e da teoria da música, negando a história "événementielle", assim como vinham fazendo também os historiadores, e centrando seus interesses nas 
análises das condições gerais da história, do gosto e da longa duração, ou seja, a mescla entre o ponto de vista diacrônico (a música como documento) e do ponto de vista sincrônico (a música como monumento) (DAHLHAUS 1983). Ele apontou ainda a necessidade de historicizar todas as atividades humanas, assim como realizar a articulação da história sobre o tempo, tomando como paradigma os questionamentos levantados pela história dos conceitos, próximo ao que vinha sendo desenvolvido, no mesmo período, pelos trabalhos de Koselleck (GREER 2000, p. 269).

Durante a década de 1980, as ciências humanas se abriram para debates interdisciplinares e para a aproximação dos apontamentos das ciências vizinhas. Este movimento de ampliação de diálogos entre vários campos de investigação foi fundamental nos estudos musicológicos para o desenvolvimento e maior visibilidade de determinadas áreas de estudo, como a etnomusicologia. Também denominada de Antropologia Musical pelo antropólogo americano Alan Merriam, em seu trabalho de definição da área - The Anthropology of Music (1964) - ela tem como objeto de estudo as práticas musicais enquanto cultura, enfocando, sobretudo, as práticas musicais de grupos sociais específicos, como índios, povos africanos, asiáticos, ou seja, priorizando as produções musicais realizadas fora do contexto cultural do ocidente tido como civilizado, cujo exemplo de conduta e prática é dado pelas culturas de matriz europeia. De certa forma, apesar da etnomusicologia ter se beneficiado desta ampliação dos diálogos entre diversas áreas de conhecimento, ela manteve-se à parte em relação à musicologia 234 histórica, que ainda apresentava resistência à abertura para práticas e sistemas interpretativos externos.

Por outro lado, o desafio lançado às ciências humanas, no final da década de 1980, foi o inverso do precedente. A atenção não estava mais diretamente ligada à busca por inovações das disciplinas e avanço no campo epistemológico, mas numa crítica de seus postulados. Também a musicologia histórica vem reexaminando sua forma de produção de conhecimento, desde meados da década de 1980, mas esta preocupação com o estudo da história da historiografia musical só teve maior expressão a partir do início do século XXI.

A constatação do isolamento no qual foram mantidos os estudos da história da música, fez com que diversos pesquisadores buscassem abranger em seus trabalhos outras linguagens interpretativas, abrindo novos campos de pesquisa e direcionamentos teóricos, como o pós-estruturalismo, os estudos de gênero, o psicanalítico, entre outros. Aos poucos estes musicólogos começam a ocupar territórios ainda pouco explorados. Mas, este caminho implica em aceitar que a musicologia não deve se reduzir unicamente à escrita de fatos colocados em ordem cronológica e tomar consciência da multiplicidade de sistemas de representação que se cruzam, como o do autor, o do público e o da música.

A musicologia revisitada, ou seja, os questionamentos dos aspectos teóricos postos após 1989, como argumenta Vendrix, é guiada pela noção de apropriação e coloca no presente o centro de gravidade do temporal. A musicologia passa a entender-se como um agir no presente. Graças a esta perspectiva, novas orientações foram integradas ao discurso musicológico. A narração passou a 
constituir-se como a mediação indispensável para a elaboração de uma obra histórica, ligando assim, o espaço de experiência e o horizonte de expectativa, chave explicativa de Koselleck na História, e endossado na musicologia por autores como Vendrix, Taïb e Legrand. Estes apontamentos da musicologia histórica são provenientes da abertura para diálogos com historiadores, principalmente aqueles ligados ao Annales pós-1970.

Apesar desta abertura para o diálogo com a história, alguns entraves ainda se apresentam, como a dificuldade que reside na definição de seu objeto, a música, assim como na elaboração do discurso, o qual depende de repensar a noção de evento e de contexto e a relação entre a compreensão da totalidade e da restituição do detalhe em sua singularidade.

O que é a música? Qual é a relação das músicas e dos compositores? Qual é a relação da música e da realidade? Qual é a relação da música e do público? Qual é a relação da música e da linguagem musical? Como compreender a tradição musical, sob seu aspecto dinâmico (a história) da mesma forma que sob seu aspecto estático (o valor)? (VENDRIX 2004, p. 1). São interrogações colocadas por Vendrix nos questionamentos iniciais apresentados em seu texto Les conceptes de I'histoire de la musique, de 2004, as mesmas que ressoam em vários outros trabalhos, cuja inquietude busca reavaliar a produção historiográfica da música até os dias atuais, como forma de rever os caminhos possíveis a serem tomados.

Dessa forma, estes questionamentos estão no cerne das inquietações da musicologia histórica, que nos últimos anos vem buscando suprir as suas lacunas abrindo suas fronteiras para diálogos com outros domínios das ciências humanas. Mas, e no que diz respeito à música como objeto de estudo da história? Há ainda caminhos a serem percorridos. A barreira colocada pela linguagem musical parece até então dificultar a análise de obras musicais como fontes históricas. Por outro lado, de forma geral, a história também não se demonstra interessada nos questionamentos apresentados pela musicologia histórica, assim como em manter diálogos com esta área de pesquisa, proporcionando a abertura de novos campos investigativos dentro da história, que contemplasse não apenas a música como produto social, forma pela qual esta arte vem sendo estudada dentro do que é conhecido como história social da música, mas que visse as obras musicais como linguagem, como documento em si, observando suas especificidades, permitindo que também a música ganhe espaços como aqueles já conquistados pelas artes plásticas, cinema, fotografia e literatura.

\section{Referências bibliográficas}

ASSIS, Ana Cláudia de; LANA, Flávio Barbeitas Jonas Lana; FILHO, Marcos Edson Cardoso. Música e história: desafios da prática interdisciplinar. In: BUDASZ, Rogério (Org.). Pesquisa em música no Brasil: métodos, domínios, perspectivas, Goiânia: ANPPOM, 2009.

BACHMAN. Philippe. La musicologie en France entre impasse et mutation: état des lieux et enjeuxpolitiques. Paris: Ed de la Maison des sciences de I'homme, 1992 
BARROS, José D'Assunção. A imaginação musical como um modelo de análise para a História Intelectual. Tempos Históricos, v. 19, p. 42-64, 2015.

BARROS, José D'Assunção. A Imaginação Musical como um modelo possível para repensar a Teoria da História. História e Cultura, v. 2, p. 4-26, 2013.

BARROS, José D'Assunção. Acordes Teóricos? A música como um modelo para a Teoria na História e em outros campos de saber. Lusíada, Série de História, v. 9, p. 11-38, 2013.

BECKER, Carl. Annual address of the president of the American Historical Association. The American Historical Review, v. 37, n. 2, p. 221-36, 1931.

BENTIVOGLIO, Júlio. Cultura Política e Historiografia Alemã No Século XIX: A Escola Histórica Prussiana e a Historische Zeitschrift. História da Historiografia, n. 6, p. 81-101, 2011.

BLANCO, Pablo Sotuyo. "Diagnóstico, estratégias e caminhos para a musicologia histórica brasileira". In: Música Hodie. Vol. 4, no 2, 2004, p. 93-102.

$\mathrm{BLOCH}$, Marc. Apologia da História ou o oficio de historiador. Rio de Janeiro: Zahar, 2001.

BLOMBERG, Carla. História da música no Brasil e musicologia: uma leitura preliminar. Projeto História, n. 43, dez. 2011.

2.36 BOURDÉ, Guy. MARTIN, Hervé. Les écoles Historiques. Éditions du Seuil, 1983.

CHIMÈNES, Myriam. Histoiresans musique. Bulletin de la société d'histoiremoderne et contemporaine, n. 1-2, p. 12-21, 1997.

DAHLHAUS, Carl. Foundations of Music History. Cambridge; New York: Cambridge University Press, 1983.

DOSSE, François. A história em migalhas. Campinas: Ed. Unicamp, 1992.

DOSSE, François. História. Bauru: Edusc, 2003.

DOSSE, F. História e Ciências Sociais. Bauru: Edusc, 2004.

FEBVRE, Lucien. Combates pela história. Lisboa: Ed. Presença, [s/d].

FEBVRE, Lucien; BERR, Henri. History. In: Encyclopaedia of the Social Sciences. New York: The Macmillan Company, 1932.

FUKUYAMA, Francis. O fim da História e o Último Homem. São Paulo: Ed. Gravita, 1999.

GREER, David. Musicology and sister disciplines: Past, Present, Future. Oxford University Press, 2000.

HARTOG, François. Experiências do tempo: da história universal à história global. história, histórias, v. 1, n. 1, 2013. 
IGGERS, Georg. The German Conception of History: The National Tradition of Historical Thought from Herder to the Present. Hanover: Wesleyan University Press, 1983.

LE GOFF, Jacques. Memória e história. Campinas: Unicamp, 2013.

KOSELLECK, Reinhart. Futuro Passado. Rio de Janeiro: Contraponto, 2006, p. 25.

Estratos do tempo. Rio de Janeiro: Ed. PucRio, 2014.

MERRIAM, Alan. The Anthropology of Music Evanston. Evanston: North Western University 1964.

SANT'ANNA. Edson Hansen. As musicologias na Atualidade brasileira: o jogo do saber e seus paradoxos. Revista Vórtex, v. 4, n. 1, 2016.

SCHOLTZ, Gunter. O problema do historicismo e as ciências do espírito no século XX. In: História da Historiografia, n. 6, , p. 42-63, 2011 [1989].

VALÉRY, Paul. Essais quasi politiques. Paris: Gallimard, 1957.

VENDRIX, Philippe, Aux origines d'une discipline historique. La musique et son histoire en France aux XVIIe et XVIIIe siècles. Genève: Droz, 1993.

VENDRIX, Philippe. Historical science and cognitive science of music. Ways towards a conciliation. In: Perception and Cognition of Music. Hove: Psychology Press, 1997, p. 69-80.

VENDRIX, Philippe. Les conceptions de I'histoire de la musique. In: NATTIEZ, Jean-Jacques. Musiques. Une encyclopèdie pour le XXIe siècle: Les savoirs musicaux. Actes Sud: Citè de la musique, 2004, p. 628-648. v. 2. 